\title{
A figura mitológica de Adamastor como ligação entre Saramago, Fernando Pessoa e Camões em $O$ ano da morte de Ricardo Reis, de José Saramago
}

\author{
Maria Elena Pinheiro Maia \\ Universidade de São Paulo
}

\begin{abstract}
Imperdoável esquecimento, disse, não ter posto o Adamastor na Mensagem, um gigante tão fácil, de tão clara lição simbólica, vê-o daí, Vejo, pobre criatura, serviu-se o Camões dele para queixumes de amor que provavelmente lhe estavam na alma, e para profecias menos do que óbvias, anunciar naufrágios a quem anda no mar, para isso não são precisos dons divinatórios particulares, Profetizar desgraças sempre foi sinal de solidão, tivesse correspondido Tétis ao amor do gigante e outro teria sido o discurso dele. ${ }^{1}$
\end{abstract}

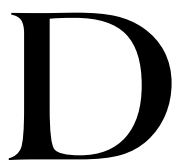

entro da narrativa pós-moderna é difícil conceber um texto como completamente independente de toda cultura já desenvolvida ao longo do tempo; poderá, é claro, ser autônomo e criativo, mas jamais negar a sua relação com os demais já existentes. Como bem lembra Laurent Jenny ${ }^{2}$ em "A estratégia da forma", a crítica formal mostrou que a intertextualidade tem implicações com o "funcionamento" da literatura: de maneira implícita ou explícita todo texto refere-se a outros textos e essa relação pode tratar-se de imitação, paródia, citação, montagem, plágio, etc.

\footnotetext{
${ }^{1}$ SARAMAGO, 1986. p. 227-228.

${ }^{2}$ JENNY, 1979. p. 7.
} 
Em "Modes et formes du narcissisme littéraire", Linda Hutcheon dá como provável que o interesse demonstrado por numerosos romances modernos de refletir sobre o próprio romance explica a intenção de parodiar, que é fundamental nesse gênero desde D. Quixote. Os escritores voltam-se com freqüência para as propriedades formais da ficção literária porque estas constituem matéria prima tão real ou irreal quanto às outras, exteriores, empíricas. Por outro lado, diz ainda Hutcheon, o romance moderno revelaria "uma certa curiosidade que o leva a ver em que medida a arte é capaz de produzir uma ordem 'real' , mesmo que por analogia, construindo uma ficção literária", fato que mostra essa "necessidade nova de criar ficções, de admitir seu caráter fictício, e de examinar suas motivações com um olhar crítico". ${ }^{3}$ Isto nos leva justamente às palavras de João Alexandre Barbosa:

Por isso, é possível dizer que, na esteira do que há de mais inovador na narrativa moderna e pós-moderna, o romance de Saramago é uma prolongada discussão acerca das relações possíveis entre a representação da realidade pela linguagem da narrativa e das inserções operadas pela imaginação ficcional. ${ }^{4}$

Ora, essa narrativa narcisista, quando exibe seus sistemas ficcionais aos olhos do leitor, espera deste, juntamente com o prazer da leitura, uma nova responsabilidade, o mesmo uso da imaginação já demonstrado pelo autor.

Além disso, a determinação do grau de explicitação da intertextualidade nas obras é problemática. Ela depende da sensibilidade dos leitores, a qual, por sua vez depende da cultura e da memória de cada época, tanto quanto das preocupações formais de seus escritores. Percebe-se, portanto, segundo Laurent Jenny, que "os modos de leitura de cada época estão igualmente inscritos nos respectivos modos de escrita."

A obra O ano da morte de Ricardo Reis requer, portanto, de seus leitores um conhecimento prévio de outros autores portugueses, principalmente de Fernando Pessoa e a problemática de sua heteronímia

\footnotetext{
${ }^{3}$ HUTCHEON, 1977. p. 90-106.

${ }^{4}$ BARBOSA, 1998. p. 5.

${ }^{5}$ JENNY, 1979. p. 7.
} 
e de Camões, bem como uma visão geral crítica da história política da Europa, especialmente de Portugal e da época na qual a obra está inserida. Não quero dizer com isso que um leitor comum não possa se deleitar com sua leitura, apenas a compreenderá num outro nível, perdendo muito de sua complexidade artística.

Ao penetrarmos nessa teia labiríntica, seremos fortemente atraídos por vários elementos míticos que percorrem todo o romance com o objetivo, cremos nós, de auxiliar-nos na resolução desse grande enigma que é o texto saramaguiano. Deter-nos-emos, no momento, na figura mitológica do gigante Adamastor que vêm ao encontro do que desejamos elucidar da leitura que ora fazemos.

Em Mitologias, Barthes fez ver que o mito contemporâneo não se anuncia mais em grandes narrativas constituídas, mas somente em discurso, apresentando-se como uma fraseologia, um corpus de frases, de estereótipos, desaparecendo, mas, ao mesmo tempo, fazendo permanecer de maneira insidiosa o mítico.

Prova disso é vermos a mitologia greco-romana ainda demasiadamente arraigada no pensamento ocidental. Há aproximadamente vinte e cinco referências ao gigante Adamastor em $O$ ano da morte de Ricardo Reis, figura mitológica inserida em Os Lusíadas por Camões, que teria reunido, segundo Francisco da Silveira Bueno, dois adjetivos para caracterizar o gigante - indomável e invencível - o primeiro inspirado em Eneida de Vergílio (Adamastor, indomável) e o segundo na Ilíada de Homero (Damastor, o domador). Ao lado dessas qualidades necessárias ao guardião dos confins do mundo, Adamastor apresenta também o seu lado vulnerável: não é suficientemente forte para suportar uma desilusão amorosa. Adamastor representa, portanto, uma figura de dupla face - a épica e a lírica.

Adamastor foi um dos gigantes que lutaram contra Júpiter com o objetivo de agradar Dóris e merecer o amor de Tétis, mas foi ludibriado e menosprezado por sua fealdade, convertendo-se de tanta mágoa e dor em terra dura, representado geograficamente pelo Cabo das Tormentas.

Camões o coloca em Os Lusiadas como obstáculo a ser enfrentado pelos portugueses. Essa ultrapassagem significa a valorização do homem português inserido na ideologia imperialista das grandes conquistas, obsessão do povo português espremido entre seu concorrente peninsular e o mar, único caminho por onde poderia se expandir. Como afirma Pedro Lyra: 
A última tática ideológica de infundição do imperialismo consiste no engrandecimento dos obstáculos, com um objetivo muito claro: engrandecer na mesma proporção o mérito de quem os ultrapassa. Isso está bem nítido nas duas ordens de obstáculos que os portugueses têm de ultrapassar: uns, naturais ou físicos, como o mar e os adversários: outros sobrenaturais ou alegóricos, como Adamastor ou Baco. ${ }^{6}$

Embora esse pensamento esteja subjacente no poema, isso não quer dizer que Camões tenha colocado sua genialidade a serviço do imperialismo. Soube muito bem contrapor a essa ideologia uma outra mais humana e igualitária principalmente expressa pela fala do velho do Restelo.

Ao reconstruir os acontecimentos históricos e a paisagem de Lisboa no ano de 1936, Saramago coloca em relevo a estátua do gigante Adamastor que servirá como motivação a uma série de reflexões: sobre o sentimento que Fernando Pessoa nutria em relação a Camões; sobre como a ideologia Salazarista se utilizou do texto camoniano; e sobre a finalidade de Adamastor em Os Lusíadas, em Mensagem e em O Ano da morte de Ricardo Reis.

A presença insistente de Adamastor leva-nos a pensar que sua utilização não é apenas uma metáfora pré-fabricada, uma petrificação do tempo e da história, mas, como já dissemos, faz parte da tessitura da obra e oferece-nos diversas leituras, pois Saramago transporta essa figura mitológica com toda a complexidade que ela já possuía em Os Lusíadas e ampliada agora, ao levarmos em consideração o sentimento ambíguo que Fernando Pessoa mantinha em relação a Camões: admiração e o desejo de superá-lo.

Não há, em Mensagem, nenhum poema que reverencie o grande épico. Mas é justamente esta ausência que o fará presente em toda obra. Segundo Helder Macedo, Pessoa nunca teria perdoado o surgimento de um poeta como Camões antes dele. Fernando Pessoa, consciente de sua genialidade, desejaria transcender Camões, ser um super-Camões e para isso seria necessário desmitificar o grande poeta, rebaixá-lo para um segundo lugar. Até o surgimento de Mensagem (1934), a Pátria de Guerra Junqueiro era para ele, a obra capital da Literatura portuguesa. Essa

\footnotetext{
${ }^{6}$ LYRA, 1985. p. 38.
} 
escolha deixa implícito que sua intenção, ao deslocar Os Lusiadas, é a de fazer de Mensagem automaticamente a expressão máxima da nacionalidade portuguesa.

Eduardo Lourenço também nos confirma esse posicionamento de Pessoa.

Camões existia e sabemos todos, depois de Gaspar Simões, que Pessoa entrou em literatura anunciando um Super-Camões, quer dizer anunciando-se como Super-Camões. Esta profecia megalomânica insere-se no sistema ou na estrutura que noutra ocasião intitulei de 'imaginação ciumenta' . Toda a obra de Pessoa é uma disputa concreta com outra obra sobre que se apoia para a transcender ou lhe imprimir um desvio que inteiramente a desloca, na forma e na substância, do seu lugar matricial. ${ }^{7}$

Confrontemos o exposto com o fragmento abaixo transcrito no qual Saramago retoma o questionamento do proposital esquecimento de Camões em Mensagem:

Quis Fernando Pessoa, na ocasião (10 de junho - festa da raça), recitar mentalmente aquele poema de Mensagem que está dedicado a Camões, e levou tempo a perceber que não há na Mensagem nenhum poema dedicado a Camões [...], então Luís de Camões sorri, a sua boca de bronze tem o sorriso inteligente de quem morreu há mais tempo, e diz, Foi inveja, meu querido Pessoa, ...8

Jorge Cury num artigo intitulado "Do Ultimatum de 1890 ao Ultimatum de 1917: da intertextualidade Pessoana " justifica esse afastamento de Pessoa em relação ao grande épico.

Que é que representa Camões tão maleficamente desprezado por Fernando Pessoa ? Simbolizava objetivamente a Redenção humana através do heroísmo português e do amor; a nacionalidade e o mito saudosista de um passado brilhante e disssipado pela aventura de Alcácer Quibir ${ }^{9}$

\footnotetext{
${ }^{7}$ LOURENÇO, 1980. p. 56.

${ }^{8}$ SARAMAGO, 1988. p. 351-352.

${ }^{9}$ CURY, 1986. p. 101.
} 
A ausência de Camões entre os heróis reverenciados por Fernando Pessoa em Mensagem talvez seja explicada, também, pelo fato de os republicanos valerem-se da imagem do poeta de Os Lusiadas como símbolo da Pátria e das grandes conquistas marítimas, enquanto Mensagem anuncia um novo tempo, propõe uma outra viagem, a de volta a terra. É a hora de dissipar o nevoeiro que paira sobre Portugal. Saraiva comprova em História Concisa de Portugal, a utilização do discurso camoniano.Vejamos:

A primeira grande vaga de propaganda patriótica foi o $3^{\circ}$ Centenário da morte de Camões, em 1880. Foram os republicanos que tomaram a iniciativa e já essa idéia estranha de fazerem de Camões um vulto tutelar da República é reveladora: é uma idéia erudita, nascida da cabeça do professor da cadeira de Literatura Portuguesa no Curso Superior de Letras, Teófilo Braga. Para ele, Camões representava a Pátria; obviamente, simbolizava a República. ${ }^{10}$

E o discurso camoniano novamente será utilizado, anos mais tarde, por Salazar que oficializará a imagem do poeta a fim de que ele possa servir a seus interesses colonialistas, pois as grandes navegações eram parte essencial da ideologia oficial, sendo a justificativa utilizada para a manutenção de um império colonial numa época em que os outros países europeus já tinham superado essa retrógrada visão política. Atentemos para o fragmento abaixo no qual Saramago ironiza essa ideologia salazarista que deseja ocultar as injustiças do regime com as glórias do passado.

À tarde, ao regressar do almoço, reparou que havia ramos de flores nos degraus da estátua de Camões, homenagem das associações dos patriotas ao épico, ao cantor sublime das virtudes da raça, para que se entenda bem que não temos mais que ver com a apagada e vil tristeza de que padecíamos no século dezesseis, hoje somos um povo muito contente, acredite, logo à noite acenderemos aqui na praça uns projetores, o senhor Camões terá toda a sua figura iluminada, que digo eu, transfigurada pelo deslumbrante esplendor, bem sabemos que é cego do olho direito, deixe lá, ainda lhe ficou o esquerdo para nos ver, se achar que a luz é forte demais para si, diga, não nos custa nada baixála até a penumbra, à escuridão total, às trevas originais, já estamos habituados. ${ }^{11}$

\footnotetext{
${ }^{10}$ SARAIVA, 1995 . p. 346.

11 SARAMAGO, 1988. p. 351.
} 
Embora a alusão a Camões não esteja clara em Mensagem, há indícios dele no poema "Monstrengo" que nos leva a associá-lo a Adamastor, como comenta Yara Frateschi Vieira no artigo "O Monstrengo", poema da transmutação:

a posição de "O Monstrengo" na Mensagem é equivalente à do Adamastor n'Os Lusíadas, se pensarmos em termos de conteúdo narrativo e da simbologia do obstáculo a transpor que os dois contêm: o próprio título do poema de Pessoa marca com clareza a referência ao Adamastor: este é um monstro, ali estamos diante de um monstrengo. ${ }^{12}$

O fato de o monstro transformar-se em monstrengo leva-nos a pensar, como já dissemos, na ambivalência de sentimentos que Fernando Pessoa alimentava em relação a Camões. Segundo afirma Yara Frateschi Vieira no artigo supracitado: " não é de descartar a hipótese de "O Monstrengo" ser uma referência depreciativa dirigida, não ao 'morcego' , mas ao próprio Adamastor." "13 Não se trata mais do monstro quinhentista que profetizava desgraças e que estava firmemente vinculado ao rochedo do Cabo das Tormentas, o monstrengo não faz ameaças, as perguntas que dirige ao homem do leme são mais queixosas que contestatórias, não está preso, ao contrário, leve, voa à volta da nau e sua voz não é mais assustadora, mas apenas um chiado.

Adamastor representa o limite do mundo conhecido, passar além do Cabo das Tormentas significa desmistificar todas as superstições, ampliar o espaço físico do mundo europeu. Em nove das várias referências que Reis faz à estátua de Adamastor, ele observa o gigante através da vidraça da janela de sua nova residência no alto de Santa Catarina, e esse é o seu limite, aventurar-se a ultrapassá-lo é penetrar no desconhecido, talvez assumir posições que ele não deseja. Como diz ainda Yara Frateschi Vieira: "O Adamastor é uma figura condensada do desconhecido, do caótico e do indomável - quer pensemos em termos do desconhecido, do caótico e do indomável - quer pensemos em termos do desconhecido geográfico, do Outro, do futuro ou das pulsões amorosas." ${ }^{14}$ Ora, na passagem abaixo, Reis demonstra o seu medo de ultrapassar o conhecido:

\footnotetext{
12 VIEIRA, 1994. p. 117.

13 VIEIRA, 1994. p. 122.

${ }^{14}$ VIEIRA, 1987. p. 33.
} 
Eu moro aqui, é aqui que eu moro, é esta a minha casa, é esta, não tenho outra, então cercou-o um súbito medo, o medo de quem, em funda cave, empurra uma porta que abre para a escuridão, doutra cave ainda mais funda, ou para a ausência, o vazio, o nada, passagem para um não ser. ${ }^{15}$

Em Os Lusíadas, Adamastor surge envolto numa nuvem escura, carregada e desfaz-se em choro ao lembrar-se de sua frustração amorosa, sendo confundido assim com o fenômeno da natureza. A chuva, a névoa, o céu coberto também fazem parte da paisagem vista através da vidraça, acentuando, ainda mais, a solidão e a nostalgia sentida por Reis.

Em diversas passagens do texto, Reis sente-se capaz de entender a solidão de Adamastor, pois identifica-se com ele: tivesse Marcenda correspondido ao seu amor, outro poderia ter sido o seu destino.

Marcenda não veio e não virá, a casa escurece, os móveis encondemse numa sombra trémula, é possível, agora, compreender o sofrimento de Adamastor. ${ }^{16}$

sobre as costas de Adamastor cai uma já esmorecida luz, rebrilha o dorso hercúleo, será da água que vem do céu, será um suor de agonia por ter a doce Tétis sorrido de escárnio e maldizendo, Qual será o amor bastante de ninfa, que sustente o dum gigante, agora já ele sabe o que valiam as prometidas abondanças. Lisboa é um grande silêncio que rumoreja, nada mais. ${ }^{17}$

A imagem dessa figura contorcida dentro da paisagem chuvosa de Lisboa lembra-nos também a dor de um povo oprimido pela ditadura mas que um dia terá forças para fazer ecoar o seu brado de liberdade.

Podemos aproximar Reis de Adamastor quando, ao saber da morte do irmão de Lídia e de outros marinheiros que não suportavam mais ser submissos à opressão, ele " atira-se para cima da cama desfeita, esconde os olhos com o antebraço para poder chorar à vontade." ${ }^{18}$ E após expressar esse grito contido, opta por acompanhar Fernando Pessoa retirando-se de

\footnotetext{
15 SARAMAGO, 1988. p. 219.

16 SARAMAGO, 1988. p. 244.

${ }^{17}$ SARAMAGO, 1988. p. 221.

18 SARAMAGO, 1988. p. 411.
} 
cena, pois sente-se impossibilitado de qualquer ação: "Então vamos, disse Fernando Pessoa, Vamos, disse Ricardo Reis. O Adamastor não se voltou para ver, parecia-lhe que desta vez ia ser capaz de dar o grande grito."19 Do mesmo modo, Adamastor, após ter sido interpelado por Gama, emociona-se ao recordar seu sofrimento amoroso e deixa transparecer o seu lado frágil, fato que o leva a abandonar o local deixando livre a passagem: "Assi contava; e, c'um medonho choro, / Súbito d'ante os olhos se apartou. / Desfez-se a nuvem negra, e c'um sonoro / Bramido muito longe o mar soou." ${ }^{20}$

É importante levar aqui em consideração que oito anos depois da partida de Ricardo Reis para o Brasil é que a estátua de Adamastor foi erigida e por coincidência, oito anos depois do monumento ali estar, no alto de Santa Catarina, é que Reis regressa a Portugal. Essa ênfase no valor simbólico do número oito, já que ele é universalmente conhecido como o número do equilíbrio cósmico, tem para Beatriz Berrini um significado altamente metafórico, pois "Oito, sendo também o número de direções cardeais, percebe-se que Adamastor se encontra espacialmente num ponto que é o cruzamento de todos os destinos, num momento que é o do equilíbrio cósmico, duplamente"21

O fato de Reis habitar próximo à estátua do Adamastor e aí ser um de seus lugares favoritos de onde pode admirar os navios fundeados no porto, o imenso rio, as embarcações tranqüilas ou em rebelião, aliado a essa referência numérica leva-nos a pensar que se Reis tivesse a coragem de ultrapassar o já conhecido, poderia ter assistido o nascimento de uma nova época alcançada após o grande grito proferido por Adamastor.

Ao analisarmos as referências ao Adamastor em $\mathrm{O}$ ano da morte de Ricardo Reis vêm à tona todas essas associações que nos levam a crer que essa figura mitológica é utilizada por Saramago com toda essa rede de significações que a envolve .

Não é apenas através da figura de Adamastor que Saramago nos remete a Camões, mas também ao iniciar - Aqui o mar acaba e a terra principia - e terminar - Aqui onde o mar se acabou e a terra espera - o romance parodiando um verso de Os Lusíadas - Onde a terra se acaba e

\footnotetext{
19 SARAMAGO, 1988. p. 415.

${ }^{20}$ CAMÕES, 1960. p. 422.

${ }^{21}$ BERRINI, 1998. p. 83.
} 
o mar começa - com a intenção, talvez, de mostrar que são outros os tempos, que agora Portugal deve voltar-se para si próprio, tentar resolver seus mais angustiantes conflitos. Navegar por mares nunca dantes navegados foi uma façanha gloriosa, mas que pertence ao passado, reiterando, assim o pensamento de Fernando Pessoa expresso em Mensagem.

Embora essa viagem inversa não se tenha concretizado, a terra espera e essa incursão ao passado de Portugal tem a finalidade de manter viva a esperança, mesmo que sejam poucas as mudanças que Saramago consegue perceber em seu país, como deixou transparecer no seu discurso ao receber o Prêmio D. Dinis em 1986 pela publicação de O ano da morte de Ricardo Reis:

Portugal, este país que somos, é hoje, o mais atrasado da Europa. Nenhuma glória passada ou sonho futuro pode ignorar a dura realidade. Dizem-me que a nossa adesão às Comunidades (não gosto do termo integração) será aquele santo remédio que nunca conseguiremos alcançar sozinhos. Espero que os factos confirmem as esperanças, embora tenha de confessar que o meu pequeno orgulho nacional se sentiria bem mais confortado se, por nossas próprias mãos, tivéssemos trabalhado e continuado a trabalhar para nos arrancarmos, repito, por nossas próprias mãos, à pobreza, à incultura, à má saúde. Não me digam, por favor, que muito se fez. Responderia que não é muito o que vejo. ${ }^{22}$

Embora não seja muito o que ele vê, pois é demasiado lúcido para ser otimista, deixa-nos uma esperança. Há sempre a possibilidade de encontrar um caminho mais iluminado através do amor, da solidariedade, da arte e da negação de toda forma de opressão.

\footnotetext{
22 SARAMAGO, 1986. p. 8.
} 


\section{Referências Bibliográficas}

BARBOSA, J. A. "Prosa tensa”. Folha de São Paulo. Suplemento Mais! 06.12.98, p. 9.

BARTHES, R. Mitologias. Tradução de Rita Buogermino e Pedro de Souza. 8. ed. Rio de Janeiro: Bertrand, 1989.

. "Mudar o próprio objeto". In: Atualidade do mito. São Paulo: Perspectiva, 1977.

BERRINE, B. Ler Saramago: o romance. Lisboa: Caminho, 1998.

CAMÕES, L. Os Lusíadas. São Paulo: Saraiva, 1960.

CURY, J. "Do Ultimatum de 1890 ao Ultimatum de 1917: da intertextualidade Pessoana”. Estudos Portugueses e Africanos, n. 8, 1986.

HUTCHEON, L. "Modes e formes du narcissismo littéraire" Poetique n. 29. Paris:Seuil,1977. p. 90-106.

JENNY, L. "A estratégia da forma". Poétique n. 27. Trad. Clara Crabbé Rocha. Portugal: Almedina, 1979. p. 7.

LOURENÇO, E. "Camões e Pessoa". Revistra Brotéria. Cultura e Informação. Vol. III, n. 1/2/3. julho-agosto-setembro, 1980.

LUCCIOnI, G. et alii. Atualidade do mito. São Paulo: Duas Cidades, 1977.

SARAMAGO, J. O ano da morte de Ricardo Reis. 3. ed. São Paulo: Companhia das Letras, 1988.

. "O poder deve deixar-se molhar..." Jornal de Letras. Ano VI - n. 212.

Lisboa. 28 de julho a 3 de agosto de 1986. p. 8-9,

SERRÃO, J. "Que política a de Fernando Pessoa?" Jornal de Letras. Ano V n. 177. Lisboa. 26 de novembro a 02 de dezembro de 1985. p. 16.

VIEIRA, F. Y. "Adamastor, o pesadelo de um ocidental”. Colóquio Letras. n. 98. julho-agosto de 1987. p. 25-37.

. "O Monstrengo, poema da transmutação". Revista Camoniana.

Vol. 9. São Paulo. 1994. p. 117-135. 


\section{Resumo}

Saramago compõe sua obra ora transitando por entre seus próprios textos, ora reutilizando textos alheios e é realmente fascinante acompanhar esse cruzamento de falas. Embora saibamos que não conseguiremos ouvir todos os rumores que emanam desse labirinto de linguagem, procuramos neste artigo desvendar a rede de associações que interligam três grandes escritores portugueses - Saramago - Fernando Pessoa e Camões - tendo a figura do gigante Adamastor como foco gerador de sentidos.

\section{Résumé}

Saramago écrit sur oeuvre en passant tantôt par entre ses textes-mêmes, tantôt en usufruiant des textes des autres, et c'est realement fascinant d'acompagner ce croisement de parole. Quoique nous sachions que nous ne reussirons pas d'écouter tous les rumeurs qui émanent de ce labyrinthe de langage, nous essayons, dans cet article, de découvrir le réseau d'associations qui lient les trois importants écrivains portugais - Saramago, Fernando Pessoa et Camões - em ayant la figura du géant Adamastor comme le foyer qu'engendre les sens. 